\title{
STAT1 and STAT2 Null Cells Are Resistant to RNA-Induced Apoptosis Due to Deficiency in Constitutive and Inducible Apoptosis-Regulating Genes
}

\author{
Farag Bleiblo",2*, Paul Michael2, Chilakamarti V. Ramana3 ${ }^{3}$, T. C. Tai'2, Joseph E. Parrillo4, \\ Anand Kumar5, Aseem Kumar ${ }^{2}$ \\ ${ }^{1}$ Department of Microbiology, Faculty of Science, University of Benghazi, Benghazi, Libya \\ ${ }^{2}$ Department of Chemistry and Biochemistry and the Biomolecular Sciences Programme, Laurentian University, Sudbury, Canada \\ ${ }^{3}$ Department of Medicine, Dartmouth-Hitchcock Medical Center, Dartmouth Medical School, Lebanon, NH, USA \\ ${ }^{4}$ Division of Cardiovascular Disease and Critical Care Medicine, Cooper University Hospital, Robert Wood Johnson Medical \\ School, Camden, NJ, USA \\ ${ }^{5}$ Section of Critical Care Medicine, University of Manitoba, Winnipeg, Canada \\ Email: *fx_bleiblo@laurentian.ca
}

How to cite this paper: Bleiblo, F., Michael, P., Ramana, C.V., Tai, T.C., Parrillo, J.E., Kumar, A. and Kumar, A. (2020) STAT1 and STAT2 Null Cells Are Resistant to RNA-Induced Apoptosis Due to Deficiency in Constitutive and Inducible Apoptosis-Regulating Genes. American Journal of Molecular Biology, 10, 165-187. https://doi.org/10.4236/ajmb.2020.103012

Received: April 26, 2020

Accepted: July 4, 2020

Published: July 7, 2020

Copyright $\odot 2020$ by author(s) and Scientific Research Publishing Inc. This work is licensed under the Creative Commons Attribution International License (CC BY 4.0).

http://creativecommons.org/licenses/by/4.0/

\begin{abstract}
Although much progress has been made in identifying the signaling pathways that mediate viral RNA-induced apoptosis and activation of interferon-stimulated genes, the role that bacterial RNA plays in regulating these responses has remained undetermined. Herein, we identified bacterial RNA as a novel inducer of the apoptotic cell death. Unlike the parental cells, STAT1 and STAT2 mutants display apoptotic defects which were reversed by restoring the expression of wild type proteins. While STAT1 mutants lacking tyrosine-701 or a functional SH2 domain were effective as the wild-type protein in restoring the apoptotic response, the mutant carrying a point mutation at serine-727 of STAT1 was resistant to bacterial RNA-induced apoptosis. We also determined that the lack of apoptosis in the STAT1 and STAT2 mutants was correlated with the constitutive and inducible activation of apoptosis regulating proteins. Furthermore, we show that bacterial RNA induces transcriptional activation of STAT1, STAT2, IRF1, and ISGF3, which was impaired in STAT1 or STAT2 mutants. These observations suggested that the participation of STATs in regulating the apoptotic response is independent of their downstream functions as cytokine-induced transcriptional activators. In addition to bacterial immunity, the results presented here may also have implications in cellular pathophysiology and RNA-based therapy.
\end{abstract}




\section{Keywords}

STAT1, STAT2, Apoptosis, Bacterial RNA

\section{Introduction}

Discriminating self from foreign is crucial to innate immunity that employs patterns recognition receptors (PRRs) to sense molecular patterns associated with pathogenic invaders. Evidence that has accumulated recently indicated that distinct PRRs sense nucleic acids released from infectious organisms, resulting in activation of intracellular signaling cascades [1] [2] [3] [4]. Of considerable interest are the recent findings that natural bacterial RNA and synthetic oligoribonucleotides can induce antigen-specific immunity, secretion of proinflammatory cytokines and type I interferons (IFNs) [5]-[18].

To exert their biological effects on targeted cells, IFNs bind to their receptors which results in the activation of intrinsic receptor tyrosine-kinase activity or receptor-associated kinases such as the Janus kinases (JAK) family of kinases [19]. The activated JAKs in turn phosphorylate specific tyrosine motifs in receptor endodomains to recruit specific monomeric signal transducer and activator of transcription (STATs) [20]. Type I IFNs phosphorylates STAT1 and STAT2 form IFN-stimulated gene factor-3 (ISGF-3), a ternary complex that also includes interferon regulatory factor 9 (IRF9). This multimeric transcription factor translocates into the nucleus and regulates gene expression by binding to interferon stimulated response element (ISRE) in the promoters of regulated genes [21] [22]. IFN- $\gamma$ induces the formation of STAT1 homodimers which in turn translocates into the nucleus, where they bind to distinct $\gamma$-activated sequence (GAS) in the promoters of target genes.

From a standpoint of the innate immunity, both bacterial and viral RNA share several immunostimulatory potential. For example, recognition of either bacterial or viral RNA induces antigen-specific immunity and secretion of proinflammatory cytokines [4]-[9]. Bacterial RNA also shares certain structural elements with viral RNA such as the 5 'triphosphate RNA which has been identified as a ligand for the retinoic acid-inducible gene I (RIG-I) and protein kinase R (PKR) [16] [23]. Both RNA ligands can also stimulate the same immuoreceptor such as NACHT, LRR and PYD domains-containing protein 3 (NALP3) inflammasome and toll-like receptor (TLR)7 [12] [13]. It is well established that innate immunity-mediated detection of viral dsRNA can modulate the JAK/STAT signaling and trigger apoptotic response. However, to our knowledge there have been no reports describing the contribution of bacterial RNA in these processes.

\section{Materials and Methods}

\subsection{Cell Lines and Treatments}

The human fibrosarcoma cell line 2fTGH was derived from HT1080. The 
2fTGH and its deficient variants: U1A (TYK2-/-), U2A (IRF9-/-), U3A (STAT1-/-), U4A (JAK1-/-), U5A (IFNAR2-/-) and U6A (STAT2-/-) were previously described [24] [25] [26]. U3A-R and U6A-R cells are U3A and U6A cells reconstituted with STAT1 and STAT2 respectively by stable transfection with expression vectors. We also employed several STAT1 mutants including Tyr 701 mutant (U3A-701); Ser 727 mutant (U3A-727); SH2 domain mutant (U3A-SH2), and the truncated variant of STAT1 (STAT1 $\beta$ ). Cells were grown to $70 \%$ confluence in DMED medium supplemented with $10 \%$ fetal bovine serum and $1 \%$ penicillin/streptomycin and then the growth medium was replaced with unsupplmented base DMED for $18 \mathrm{~h}$ before treatment. Approximately $2 \times 10^{6}$ cells were stimulated with or without $100 \mu \mathrm{g} / \mathrm{ml}$ bacterial total RNA or digested total RNA for $24 \mathrm{~h}$ or $48 \mathrm{~h}$.

\subsection{Preparation of Bacterial Total RNA}

Pathogenic isolates of E. coli (O18:K1:H7; ATCC \#700973) were used for this study. A modified hot phenol combined with enzymatic lysis was carried out to isolate bacterial total RNA. Exponentially growing bacteria were harvested in ice cold 5\% phenol/ethanol solution and then resuspended in a fresh lysis buffer of TE and $2 \mathrm{mg} / \mathrm{ml}$ lysozyme (Sigma Aldrich, St. Louis, USA). Samples were brought to $2 \%$ SDS and a volume of $850 \mu \mathrm{l}$ water-saturated phenol was added to each tube and incubated for 5 minutes at $64^{\circ} \mathrm{C}$. Following centrifugation at $13,000 \mathrm{X} \mathrm{g}$, the aqueous phase was transferred to a fresh tube and equal amounts of chloroform were added and centrifuged for 10 minutes at $4^{\circ} \mathrm{C}$. The RNA was precipitated by $0.1 \mathrm{vol} 3 \mathrm{M}$ sodium acetate and $2.5 \mathrm{vol}$ ethanol. The RNA pellets were washed with $70 \%$ ethanol and resuspended in DEPC-treated water. The integrity and purity of RNA species were determined by electrophoresis on agarose gels and A260/A280 ratios. Extracted crude RNA was treated with RNase-free DNase I (Roche, Indianapolis, USA) to remove contaminant genomic DNA and further purified by the Qiagen method (Qiagen, Valencia, USA) as per the manufacturer's instructions.

\subsection{RNA Digestion}

Aliquots of RNA samples were incubated in the presence of a heterogeneous mixture of ribonucleases ( $1 \mathrm{U}$ per $2 \mu \mathrm{l}$ of RNA at $1 \mu \mathrm{g} / \mu \mathrm{l}$ for $1 \mathrm{hr}$ ) (Roche, Indianapolis, IN). RNA samples were analyzed by denaturing agarose or polyacrylamaide gel electrophoresis for quality assurance. Aliquots of digested total bacterial RNA were added to the media to yield a final concentration of 100 $\mu \mathrm{g} / \mathrm{ml}$.

\subsection{Immunoprecipitation and Immunoblotting}

Cells were challenged with bacterial RNA to test their ability to induce apoptosis. The treated and non-treated cells were washed three times with cold PBS, and then the cell pellets were resuspended in Radioimmunoprecipitation assay 
(RIPA) lysis buffer (PBS, 1\% Igepal, $0.5 \%$ sodium deoxycholate, $0.1 \%$ SDS) plus a protease inhibitor mixture and incubated on ice. For immunoprecipitation, $500 \mu \mathrm{g}$ of the cellular lysates were first precleared with the addition of $50 \mu \mathrm{l}$ of $50 \%$ protein $\mathrm{G}$-Sepharose beads (Santa Cruz) for $1 \mathrm{~h}$ at $4^{\circ} \mathrm{C}$ under rotation and recovered. The supernatants were incubated with $5 \mu \mathrm{l}$ of antibodies specific for the target proteins for $30 \mathrm{~min}$ on ice and then $50 \mu \mathrm{l}$ of $50 \%$ suspension of protein G-beads in RIPA were added, and incubation was continued overnight with rotation. The beads were washed twice with RIPA, collected, and immunoprecipitates were subjected to electrophoresis. For detection of tyrosine phosphorylated proteins, membranes were probed with the anti-phosphotyrosine monoclonal antibodies PY20 (Signal Transduction Laboratories) and 4G10 (Upstate Biotechnology Incorporated). For Western blot analysis, cellular proteins were resolved by SDS-PAGE gels and transferred to PVDF membranes. The membranes were blocked and subjected to immunoblotting analysis using antibodies specific for STAT1, STAT2, JAK1, caspase-2, caspase-8, BCL2 (Cell Signaling). Caspase-3, IRF1, and p53 antibodies were from Santa Cruz. When required, mmembranes were stripped of previous antibody and reprobed for total protein forms or co-immunoprecipitation experiments.

\subsection{Electrophoretic Mobility Shift Assay (EMSA)}

Cytoplasmic extracts were prepared and assayed for EMSA as described previously [27]. Briefly, $6 \mu \mathrm{g}$ of proteins were subjected to EMSA in a binding reaction containing 200,000 cpm of [ $\left.\gamma-\mathrm{p}^{32}\right]$ ATP-end labeled oligonucleotides probes to measure the binding activity for STAT1, STAT2, IRF1, and ISGF3. The oligonucleotides used were: the high affinity ISG15 sequence

(5'-GATCCATGCCTCGGGAAAGGGAAACCGAAACTGAAGCC-3') for the ISRE, the GAS sequence 5'-TTCCGGGAA-'3 for binding to STAT1, IR element, (5'-GTGATTTCCCCGAAATGACG-3'), for binding to STAT2, and the hexamer sequence (5'-AAGTGA-3') for IRF1. For supershift experiments, the protein extracts from bacterial RNA-treated cells were incubated with $1 \mu$ of antibody against STAT1, STAT2, (from cell signaling) and IRF1 (from Santa Cruz Biotechnology) for $10 \mathrm{~min}$ at room temperature before adding the probe.

\subsection{Analysis of Genomic DNA Fragmentation}

For isolation of genomic DNA fragments, we followed the method described by Hermann et al with few modifications [28]. Briefly, cells from 10-cm plate $(2 \times$ $10^{6}$ ) were challenged with $100 \mu \mathrm{g} / \mathrm{ml}$ total bacterial RNA or digested RNA, collected, and the pellets were resuspended in lysis buffer (1\% Nonidet P-40 in 20 $\mathrm{mM}$ EDTA, $50 \mathrm{mM}$ Tris- $\mathrm{HCl}, \mathrm{pH}$ 7.5) for 15 minutes and centrifuged. The supernatants contained fragmented DNA were brought to $1 \%$ SDS and treated for 30 minutes with RNase A (final concentration $0.5 \mathrm{mg} / \mathrm{ml}$ ). Proteinase $\mathrm{K}$ was then added to a concentration of $1 \mathrm{mg} / \mathrm{ml}$ and incubation was continued for $2 \mathrm{~h}$ at $50^{\circ} \mathrm{C}$. The DNA was precipitated and resuspended in TE buffer and genomic DNA was fractionated by $1 \%$ agarose electrophoresis. 


\section{Results}

Bacterial RNA shares certain structural and signaling features with viral RNA. It is well established that viral RNA can trigger apoptosis. However, there have been no reports describing the contribution of bacterial RNA in the apoptotic response. Because DNA fragmentation is consistently used as a hallmark of apoptosis, we evaluated the potency of bacterial RNA to trigger genomic DNA fragmentation in HT1080 cells. Comparing to the untreated cells, we found that stimulation of these cells with total RNA derived from E. coli induced genomic DNA laddering (Figure 1, lane 4). To rule out the possibility that the apoptotic effects on HT1080 cells were induced by potential contaminants in the RNA preparations, we subjected bacterial RNA to enzymatic digestion with RNase and challenged the cells. Genomic DNA laddering was not apparent in cells incubated with RNase-digested bacterial RNA, confirming that bacterial RNA is the active inducer of apoptosis (Figure 1, lane 3).

Although JAK/STAT signaling is considered as a principal player in cytokine signaling, its contribution to bacterial RNA-induced apoptosis has not been reported. To determine the role of different JAK/STAT signaling components in bacterial RNA-induced apoptosis, we treated mutant cell lines lacking a single protein of JAK/STAT signaling pathway with bacterial RNA. Unlike the parental cell line 2fTGH, STAT1 mutant (U3A) and STAT2 mutant (U6A) cells were resistant to apoptosis induced by bacterial RNA in comparison to non treated cells (Figure 2(a) vs Figure 2(c), lanes 2, 5, and 8). Although the mutant cell lines lacking TYK2 (U1), p48 (U2), JAK1 (U4), IFNAR2 (U5), and JAK2 $(\gamma 2 \mathrm{~A})$, are defective in IFN signaling, the apoptotic response of these mutants was similar to $2 \mathrm{fTGH}$ and $2 \mathrm{C} 4$ cells (the parental cell line for $22 \mathrm{~A}$ ). RNase-digested bacterial RNA failed to trigger DNA fragmentation confirming that bacterial RNA is the actual inducer of apoptotic cell death (Figure 2(b)). The apoptotic defects in U3A and U6A cells were reversed by reintroducing these cells with full-length STAT1 and STAT2 cDNAs respectively, excluding the possibility that a mutation in another gene was responsible for these effects (Figure 3 lane 7 vs. 10 and lane 13 vs. 16).

STAT1 transcriptional activity is essential for cytokine signaling. Therefore, we tested whether the role of STAT1 in bacterial RNA-induced apoptosis requires its transcriptional activity. STAT1 dimerization, DNA binding, and gene regulation require its phosphorylation at the tyrosine 701. Furthermore, enhancing the transcriptional activity of STAT1 also requires its phosphorylation at the conserved domain 727 [29] [30]. Similarly, dimerization of STAT1 and recognition of cytokine receptors requires the SH2 domain of STAT1 [31]. In contrast to IFN-induced transcriptional regulation, we found that the STAT1 mutants U3A-701 and U3A-SH2 were not essential for apoptosis signaling and effective as the wild-type protein of $2 \mathrm{fTGH}$ to restore the apoptotic response (Figure 4, lanes 4 and 10). Interestingly, the apoptotic response was reduced in STAT1 that carrying a point mutation at the serine 727 (U3A-727) as shown in Figure 4 , lane 7. The STAT $1 \alpha$ and STAT1 $\beta$ are two alternative truncated ver- 
sions of STAT1 that vary only in the occurrence of $\mathrm{COOH}$ terminal domain [21] [32]. We found that the alternative spliced versions STAT1 $\alpha$ and STAT1 $\beta$ were similarly able to restore apoptosis in U3A cells (Figure 4, lane 13).

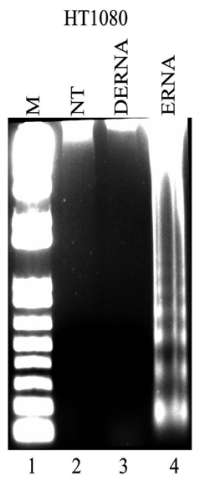

Figure 1. Bacterial RNA induces genomic DNA laddering in fibroblasts. The HT1080 cells were treated with $100 \mu \mathrm{g} / \mathrm{ml}$ intact E. coli RNA (ERNA, lane 4) or RNase-digested E. coli RNA (DERNA, lane 3) for $48 \mathrm{hrs}$ or left untreated (NT, lane 2). Small molecular weight DNA fragments were extracted and fractionated by $1 \%$ agarose gel electrophoresis. M: DNA marker.

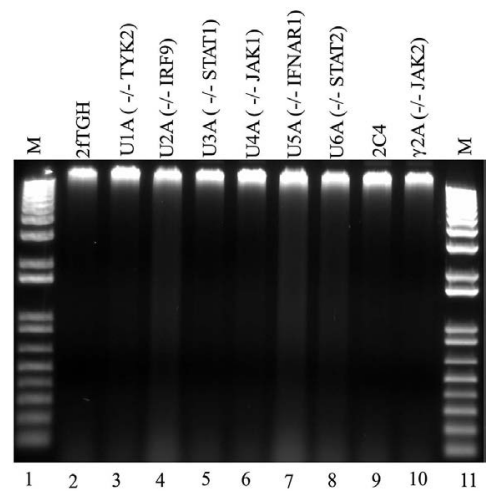

(a)

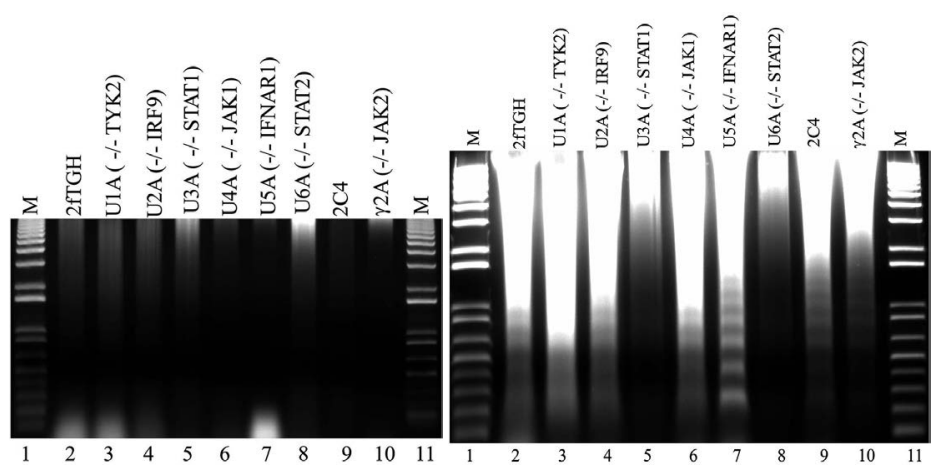

(b)

(c)

Figure 2. Analyses of genomic DNA laddering in mutants of JAK/STAT signaling pathway. The parental cell lines $2 \mathrm{fTGH}$ and $2 \mathrm{C} 4$ and their mutant versions were left untreated (panel a), treated with $100 \mu \mathrm{g} / \mathrm{ml}$ RNase-digested $E$. coli RNA (panel b) or challenged with $100 \mu \mathrm{g} / \mathrm{ml}$ intact $E$. coli RNA (panel c) for $48 \mathrm{hrs} .1 \%$ agarose gel electrophoresis performed to visualize the small molecular weight DNA fragments. M: molecular DNA marker. 


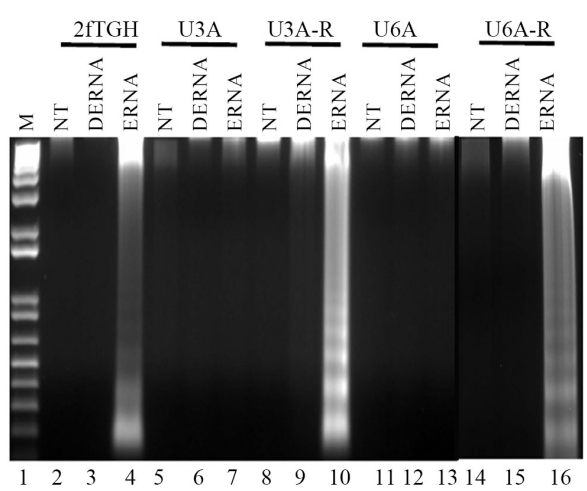

Figure 3. STAT1 null (U3A) and STAT2 null (U6A) cells are resistant to apoptosis induced by bacterial RNA. The parental cell line 2fTGH, STAT1 mutant (U3A), STAT2 mutant (U6A), U3A stably transfected with STAT1 cDNA (U3A-R), and U6R were left untreated (NT), treated with $100 \mu \mathrm{g} / \mathrm{ml}$ digested E. coli RNA (DERNA), or challenged with $100 \mu \mathrm{g} / \mathrm{ml}$ intact bacterial RNA (ERNA) for $48 \mathrm{~h} .1 \%$ agarose gel electrophoresis performed to visualize the small molecular weight DNA fragments. M: molecular DNA marker.

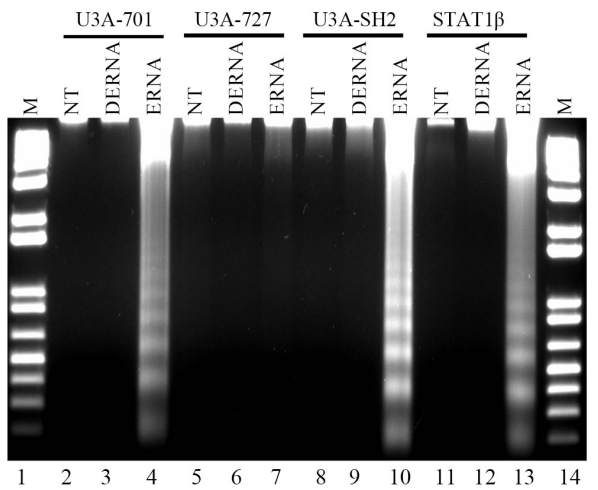

Figure 4. Transcriptional activity of STAT1 in apoptosis. STAT1 null cells (U3A) were transfected with different mutant versions carrying a mutation in STAT1 tyrosine 701 (U3A-701), serine 727 (U3A-727), SH2 domain (U3A-SH2) or the truncated version of STAT1 (STAT1ß). Genomic DNA fragments from untreated cells (NT), cells treated with either RNase-digested E. coli RNA (DERNA), or intact $E$. coli RNA (ERNA) were analyzed by $1 \%$ agarose gels. M: DNA marker.

In certain cells lines, cytokines and IFNs induce apoptosis through transcriptional induction of interferon-mediated regulation of apoptotic genes. This apoptotic response was correlated with activation and DNA binding activity of STAT proteins [29] [33] [34]. In addition, it has been recently shown that bacterial RNA induces the secretion of inflammatory cytokines and interferons. However, the underlying mechanism remains unexplored. Therefore, we sought to test the potential role of STAT activation in the apoptotic response induced by bacterial RNA. Because tyrosine phosphorylation is the major determinant of STAT1 and STAT2 activation, we first immunoprecipitated STAT1 and STAT2 from bacterial RNA-treated- and -untreated cells and then we probed the purified proteins with phosphotyrosine specific antibody. Immunoblotting analyses show that bacterial RNA induces both tyrosine phosphorylation of STAT1 and 
STAT2 in the parental HT1080 and 2fTGH cells (Figure 5(a) and Figure 5(b), third panel, lanes 1 and 2). The defects in tyrosine phosphorylation induced by bacterial RNA in U3A and U6A cells were reversed by restoring these cells with STAT1 and STAT2 respectively (Figure 5(a) and Figure 5(b), third panel, lanes 3 vs. 5 and 6 vs. 7). Interestingly, in the mutant human cell line U6A, the tyrosine phosphorylation of STAT1 is defective (Figure 5(a), third panel, lane 6). This result contrasted with the U3A cells in which STAT2 phosphorylation was normal which suggested the dependence of STAT1 phosphorylation on STAT2 (Figure 5(a), third panel, lane 6 vs. Figure 5(b), third panel, lane 3). We also observed a reduction in STAT1 tyrosine phosphorylation in STAT1 serine mutant U3A-727 suggesting interdependence of one phosphate on the other (Figure 5(a), third panel, lane 4). Again, RNase digestion of total bacterial RNA reversed the effects on tyrosine phosphorylation of both STAT1 and STAT2 (Figure 5(a) and Figure 5(b), second panel). STAT1 and STAT2 are substrates of JAK1 which is an obligatory kinase in mediating the biological responses to the major classes of cytokine receptors including both type I and II interferon receptors [35] [36]. Thus we tested whether tyrosine phosphorylation of STAT1 and STAT2 corresponds to endogenous JAK1 activation. We first immunoprecipitated JAK1 from cell lines treated with or without bacterial RNA and then subjected the purified JAK1 to immunodetection with phosphotyrosine specific antibody. The results from this assay revealed that the purified JAK1 was efficiently tyrosine phosphorylated in the parental cell lines but not in U3A and U6A cells (Figure 5(c), third panel, lanes 1and 2 vs. lanes 3 and 6). The amount of phosphotyrosine JAK1 protein in the mutant U3A-727 was also reduced suggesting the positive effects of serine phosphorylation on tyrosine of STAT1 (Figure 5(c), third panel, lane 4). We next performed EMSA to assess DNA binding activity of transcriptional factor STAT1 and STAT2 to proteins from bacterial RNA-treated and non treated cells. Consistent with our previous results, EMSA results show that bacterial RNA induced STAT1 and STAT2 transcriptional activation in the parental cell lines (Figure 6(a) and Figure 6(b), third panel, lanes 1 and 2). Consistent with previous Western experiments, EMSA results show that STAT1 activation was defective in both U3A and U6A (Figure 6(a), third panel, lanes 3 and 6). In contrast to Western blot results, we observed that STAT2 activation was not only defective in U6A, but also in U3A and U3A-727 (Figure 6, third panel, lanes 3, 4, and 6). Again, restoring STAT1 and STAT2 reverses the deficiencies in both U3A and U6A (Figure 6(a) and Figure 6(b), third panel, lanes 5, and 7). Digested bacterial RNA failed to activate STAT1 or STAT2 (Figure 6(a) and Figure 6(b), second panel). Although bacterial RNA uses components common to IFN signaling, the above results suggested that the essential role of STAT1 and STAT2 for bacterial RNA-mediated apoptosis appears to be partially independent of their function as cytokine induced transcription effectors. The transcription factors STAT1 and STAT2 are known to combine with p48 (IRF9), a DNA-binding protein, to assemble the heterotrimeric ISGF3 which binds to ISREs distinct from the IR 


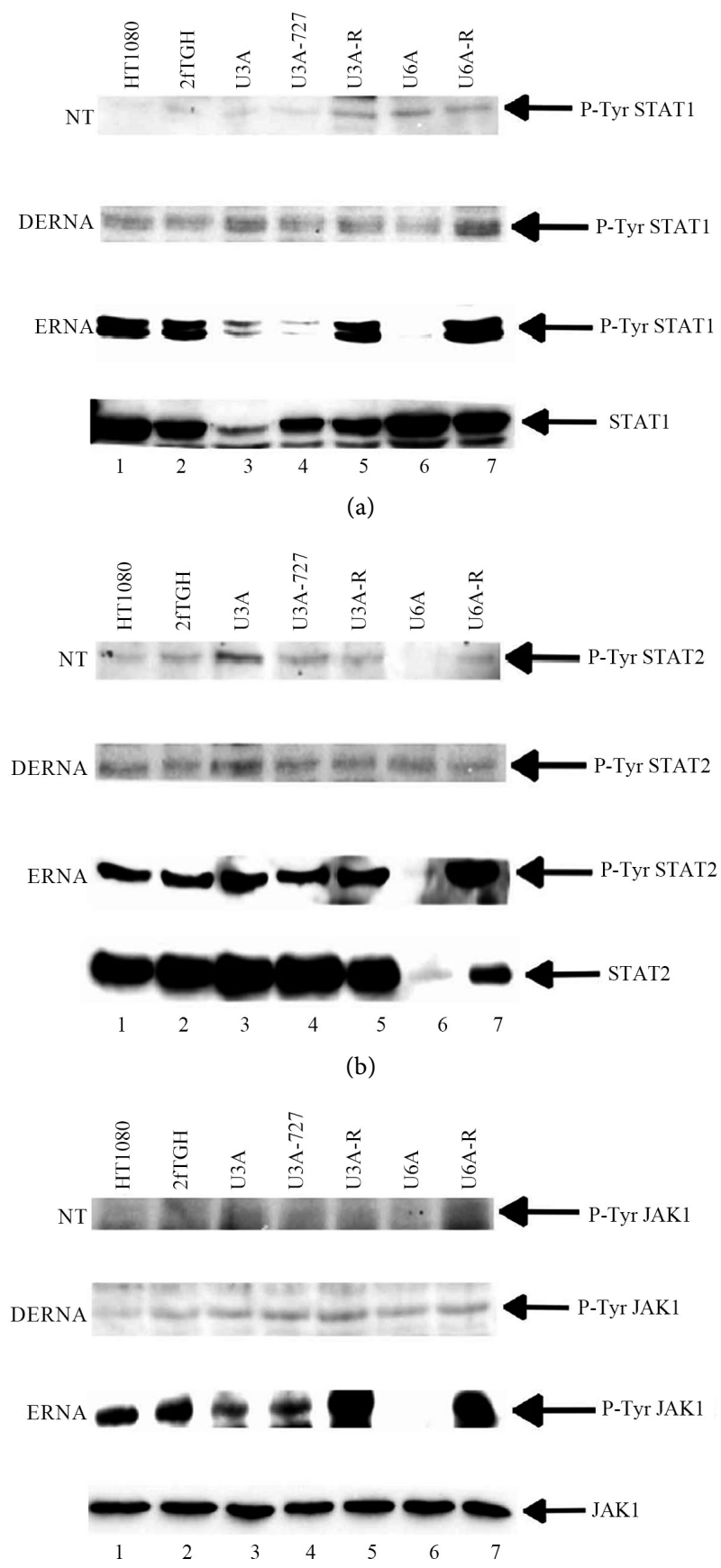

(c)

Figure 5. Induction of tyrosine phosphorylation of STAT1, STAT2, and JAK1 by bacterial RNA. The parental and mutant cell lines were not stimulated [NT] (top panel a, b, c) or stimulated for $24 \mathrm{~h}$ with either $100 \mu \mathrm{g} / \mathrm{ml}$ RNase-digested $E$. coli RNA [DERNA] (second panel a, b, c) or intact $E$. coli RNA [ERNA] (third panel a, b, c). STAT1 (a), STAT2 (b), and JAK1 (c) were first immunoprecipitated from the cells, resolved by SDS-PAGE, and Western blots were probed with phosphotyrosine specific antibodies. Membranes were stripped and reprobed with antibody for STAT1 (bottom panel a), STAT2 (bottom panel b), or JAK1 (bottom panel c). Positions of phosphotyrosine STAT1, phosphotyrosine STAT2, and phosphotyrosine JAK1 are indicated by arrows. 


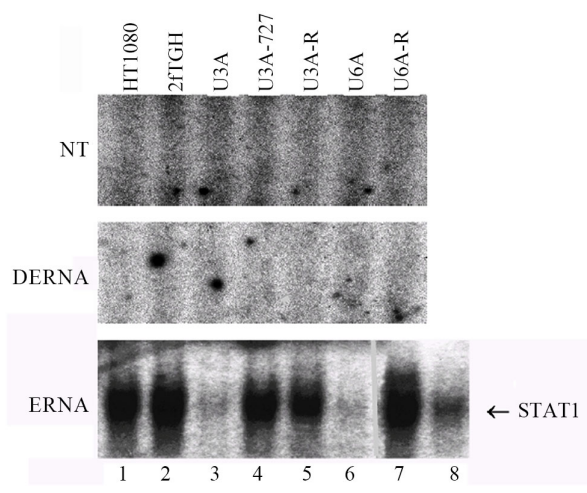

Figure 6. U3A, U3A-727, and U6A mutant cells are defective in bacterial RNA-induced activation of STAT1, STAT2, and ISGF3. EMSAs were performed with protein extracts prepared from the parental and mutant cell lines that were not treated [NT] (top panel, a, b, and c) or treated for $24 \mathrm{~h}$ with either $100 \mu \mathrm{g} / \mathrm{ml}$ RNase-digested E. coli RNA [DERNA] (middle panel a, b, and c) or intact E. coli RNA [ERNA] (bottom panel, a, b, and c). The DNA binding activities of STAT1 (a), STAT2 (b), and ISGF3 (c) were determined by using $\mathrm{P}^{32}$-labeled regulatory elements as probes for these transcriptional factors. Extracts of bacterial RNA-treated 2fTGH cells incubated with STAT1 (a, bottom panel, lane 8), STAT2 (b, bottom panel, lane 8), or bacterial RNA-treated U2A cells (c, bottom panel, lane 8 ) were used to identify these proteins.

of the IRF-1 gene [22]. Furthermore, it has been shown that ISGF3 mediate apoptosis induced by different stimuli [37] [38]. We examined whether bacterial RNA induces ISGF3 activation and whether its transcriptional activity is impaired in the U3A and U6A cells (Figure 6(c)). Our results clearly demonstrated the activation of ISGF3 in both HT1080 and 2fTGH cells (Figure 6(c), third panel, lanes 1 and 2). While its activation in U3A and U6A is defective, complementation of these mutants with constructs for STAT1 and STAT2 restored the response to bacterial RNA and the ability to form ISGF3 (Figure 6(c), third panel, lanes 3 vs. 5 and lane 6 vs. 7). These results suggested that U3A and U6A are resistant to bacterial RNA induced apoptosis due to the deficiency in the ISGF3-mediated gene regulation of apoptosis genes.

The IRF1 gene responds to IFN- $\alpha / \beta$ through utilizing AAF to activate GAS-like elements or activated by IFN- $\gamma$ through GAS elements. The induction of IRF1, which has been implicated in the regulation of apoptosis, is defective in both STAT1 and STAT2 mutants [21] [29] [39]. Thus; we first tested the basal level of IRF1 protein in the parental and mutant cell lines. Although the IRF1 protein expressed normally in U3A and U3A-727 cells, its level U6A cells decreased as determined by Western blots (Figure 7(a), lane 6). To investigate whether the lack of IRF-1 expression might be involved in the apoptotic phenotype of U3A cells, we tested the mutant U3A-IRF1 (a stable transfectant of U3A in which IRF1 expression is comparable to that of $2 \mathrm{fTGH}$ cells). Our results show that expression of IRF1 can restore the DNA fragmentation of apoptotic response in U3A, suggesting that STAT1-regulated expression of IRF1 must be required for bacterial RNA-induced apoptosis (Figure 7(b)). 


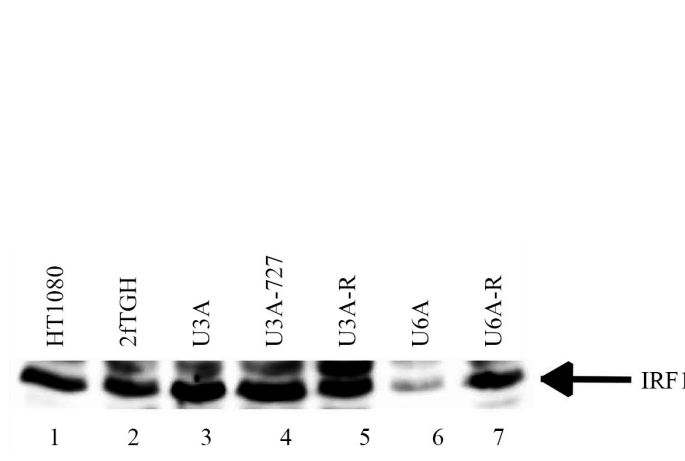

(a)

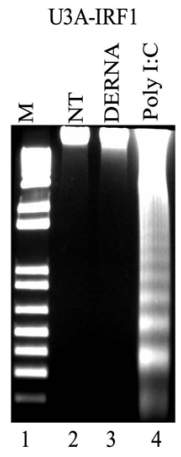

(b)

Figure 7. Analysis of IRF1 expression in STAT mutants and involvement of IRF1 in STAT1-mediated apoptosis. (a) Protein extracts from untreated parental and mutant cell lines were analyzed by Western blotting using antibody to IRF1. (b) U3A cells were stably transfecetd with IRF1 expression vector and challenged without (NT), or with RNase-digested E. coli RNA (ERNA) or intact E. coli RNA. Post-treatment, genomic DNA laddering was performed on $1 \%$ agarose. M: DNA marker.

In IFN-induced apoptosis, transcriptional induction of many apoptosis-regulating genes is mediated by tyrosine phosphorylation and DNA binding activity of STAT1 or STAT2. In contrast, microarray studies of gene expression in U3A cells and Y701F mutant (STAT1 mutant that cannot be phosphorylated on tyrosine) revealed that expression of many genes can also be regulated by unphosphorylated STAT1 [24] [40] [41]. To further understand why bacterial RNA-induced apoptosis depends on STAT1 and STAT2, we tested a number of proteins known to mediate apoptosis. The p53, a tumor suppressor transcription factor, plays central roles in regulating a wide range of biological processes including cell cycle arrest, DNA damage stress, and promoting apoptosis. Western blot analysis demonstrated that both the basal and induced levels of p53 are greatly reduced in U3A but not in U6A or the STAT-727 mutants (Figure 8, lane 3 vs. lanes 4 and 6). Reconstitution of U3A with STAT1 rescues the sensitivity of these cells to bacterial RNA-induced apoptosis and restored the expression of 553 protein to levels comparable to those in parental cell line indicating that STAT1 is a positive regulator for p53 (Figure 8, lane 5 vs. lanes 1 and 2). Co-immunoprecipitation results indicated that STAT1 is physically associated with p53 in non-stimulated cells and this interaction is enhanced by treatment with bacterial RNA (Figure 8(b), lanes 1 and 2). The STAT1 mutant U3A confirms the specificity of STAT1 association with p53 (Figure 8(b), lane 3). This result suggests the involvement of post-transcriptional events of STAT1 control in regulating bacterial RNA-induced apoptosis. The basal level of the anti-apoptotic protein BCL2 was lower in U6A cells only and increased by challenging these cells with bacterial RNA which partially may explain the resistance of these cells to apoptosis (Figure 8(c), top and third panels). Similarly, digestion of bacterial RNA fails to exert any effects on p53 or BCL2 (Figure 8(a) and Figure 8(c), second panel). 


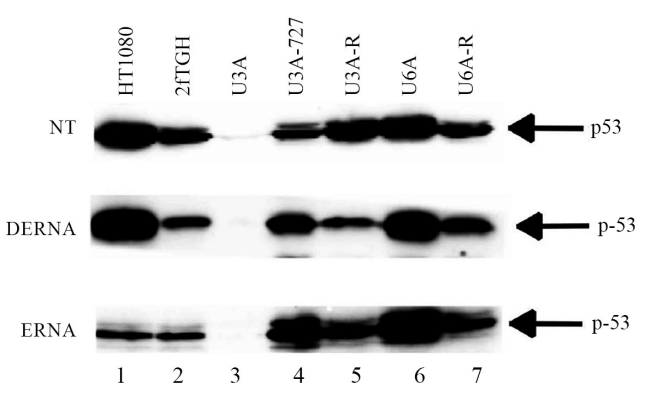

(a)

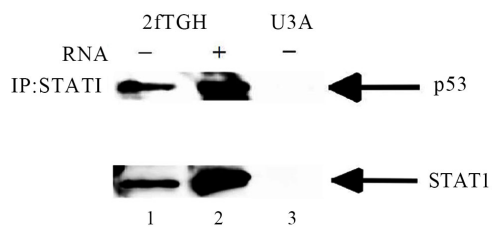

(b)

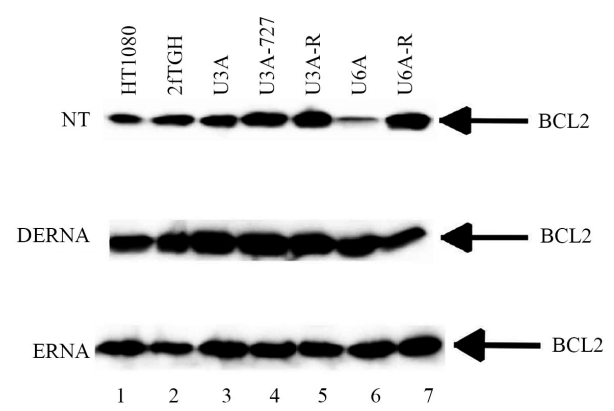

(c)

Figure 8. STAT1 and STAT2 regulate 553 and BCL2 proteins. Parental and mutant cell lines were not treated [NT] (top panel a, c) or treated for $48 \mathrm{hrs}$ with either $100 \mu \mathrm{g} / \mathrm{ml} \mathrm{di}$ gested E. coli RNA [DERNA] (second panel a, c) or intact E. coli RNA [ERNA] (third panel a, c). Cellular proteins were separated by SDS-PAGE and probed for p53 (a) and BCL2 (c). (b) STAT1 physically associates with p53. After stimulation of 2fTGH with [+] or without [-] E. coli RNA for 48 hrs, STAT1 was first immunoprecipitated, separated on SDS-PAGE, and probed with p53 antibody (top panel). Membrane was stripped and reprobed with STAT1 antibody (bottom panel). U3A was used as a negative control.

To further explore the mechanism underlying the resistance of U3A, U3A-727, and U6A cells to bacterial RNA-induced apoptosis, we studied the basal levels and cleavage of some caspase family proteins as key regulators of apoptosis. We found that the basal level of caspases-2 was lower in U3A cells and restored when the cells reintroduced with STAT1 (Figure 9(a), top panel, lane 3 vs. lane 5). However, treatment with bacterial RNA failed to induce any cleaved products suggesting STAT1-independent mechanism for activation of caspase-2 (Figure 9(a), bottom panel). Comparing to $2 \mathrm{fTGH}$, the expression of caspase-3 protein in U3A was defective, however, transfecting these cells with STAT1 cDNA, restores the expression of the protein (Figure 9(b), top panel, lane 3 vs. 5). The basal level of caspase- 3 in U3A and U3A-727 were not different from the parental cell lines. However, treatment with bacterial RNA induced caspase- 3 activation in 2fTGH, HT1080, U3A-R, and U6A-R cells which may explain the 
resistance of U3A, U3A-727 and U6A cells to apoptosis induced by bacterial RNA (Figure 9(b), bottom panel, lanes 1 and 2 vs. lanes 3, 4, and 6). We next tested the initiator caspase- 8 . The data from this experiment indicated that the constitutive levels of procaspase-8 were decreased in U3A and U3A-727 cells, but comparable to $2 \mathrm{fTGH}$ in U6A (Figure 9(c), top panel). Treatment with bacterial RNA failed to induce activation of caspase- 8 in both U3A and U3A-727 cells (Figure 9(c), bottom panel). The above results suggested that the lack of programmed cell death induced by bacterial RNA in the STAT1 and STAT2 mutants do not only correlate with lack of the constitutive but also with the inducible levels of caspases. Therefore, the mechanism that sends downstream signaling to regulate constitutive and inducible expression of STAT1 and STAT2 targeted genes seems to be distinct.

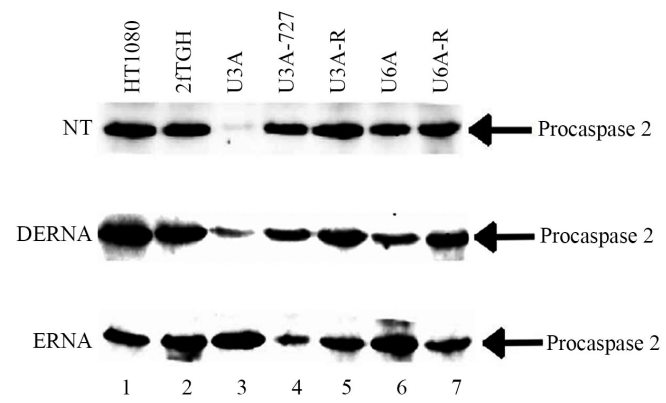

(a)

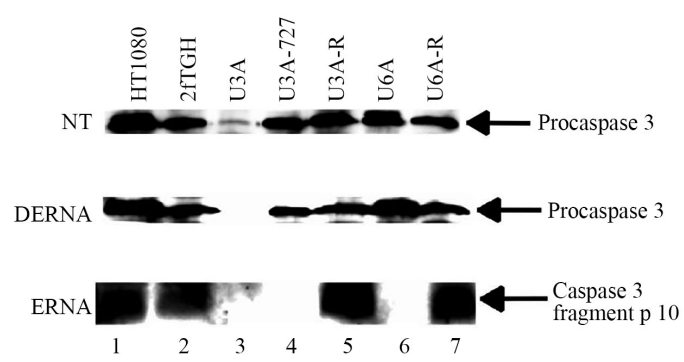

(b)

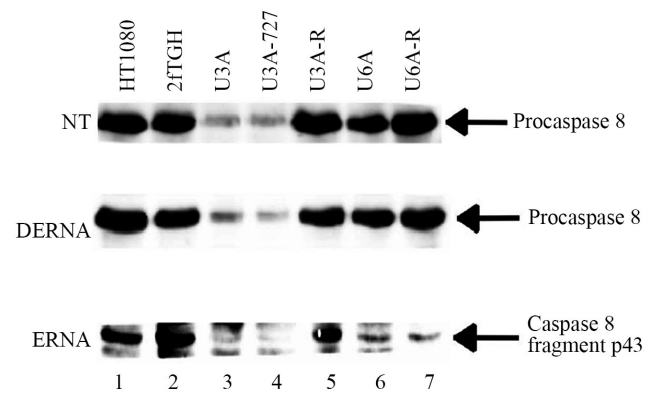

(c)

Figure 9. STAT1 and STAT2 regulate the constitutive and inducible levels of caspases. Protein extracts from parental or mutant cell lines were not teated [NT] (top panels) or treated with either $100 \mu \mathrm{g} / \mathrm{ml}$ RNase-digested $E$. coli RNA [DERNA] (middle panels) or $E$. coli RNA [ERNA] (bottom panels) for $48 \mathrm{~h}$ were resolved on SDS-PAGE and analyzed by Western blotting using antibodies to caspase-2 (a), caspase- 3 (b), or caspase- 8 (c). The procaspases forms and their cleaved fragments are indicated. 


\section{Discussion}

Nucleic acids are not only essential genetic elements, but sensing their molecular patterns is also an important quality control mechanism which has evolved to maintain the integrity of human genome. In addition to bacterial cell wall components and toxins which are considered as the principal pathogenic signatures responsible for programmed cell death, herein we identified bacterial RNA as a novel inducer of apoptosis. Bacterial RNA and modified ssRNA are potent immunostimulatory agents characterized by induction of proinflammatory cytokines such as IL- $1 \beta$, IL- 6 , IL-12, TNF- $\alpha$, IFNs, reactive oxygen/nitrogen species and thus implicated in a range of diseases [7] [8] [9] [10] [11]. We previously demonstrated that bacterial DNA and RNA derived from $S$. aureus and E. coli and poly I:C induce cardiac cell dysfunction and implicated this response in septic shock [42]. We also reported that sera derived from septic patients predisposed to bacterial infections induces apoptosis, activates transcriptional factors STAT1, NFKB, IRF1, and differentially regulates the apoptosis related genes [27] [43] [44] In vivo and in vitro studies demonstrated that natural bacterial DNA and synthetic CpG oligonucleotides induce the secretion of TNF- $\alpha$, IL-1 $\beta$, IL-6, iNOS, trigger apoptosis and thus are linked to septic shock [45] [46]. It has been shown that bacterial RNA can activate cytosolic immunoreceptors similar to those reported for DNA recognition [47] [48]. Thus, both bacterial DNA and RNA can trigger antiviral-like state characterized by programmed cell death. Loss of cellular functions by apoptosis is clearly identified as a serious and frequent complication in patients suffering from microbial infections, multiorgan failure and septic shock. These observations therefore support the concept that bacterial RNA of itself can elicit a lethal inflammatory response.

We show that STAT1 and STAT2 null cells display apoptotic defects which were reversed by restoring the expression of wild type proteins. To understand whether STAT1 is acting as a cytoplasmic signaling adaptor or a nuclear transcription factor, we examined the participation of different STAT1 subdomains in apoptosis signaling. Although the functional SH2 domain and tyrosine-701 are absolutely critical for STAT1 transcriptional activity induced by IFNs, our results indicated they were actually not required for apoptotic function since mutants of these domains were effective as the wild-type proteins in restoring the apoptotic response. Lacking the $\mathrm{COOH}$-terminal region in STAT1 $\beta$ did not protect these cells from bacterial RNA-induced apoptosis; however, a point mutation at serine-727 in the COOH-terminal region of STAT1 greatly decreased the apoptotic response. The $38 \mathrm{COOH}$-terminal amino acids segment of STAT1 is essential for transcription activation induced by IFNs through recruitment of coactivators and chromatin remodeling complexes. However, both STAT1 $\alpha$ and STAT1 $\beta$ dependent transcription was also stimulated by the TIRAP/Mediator co-activator complex on a naked DNA template [29] [49]. Our results suggest that the $\mathrm{COOH}$-terminal domain is not the only effector domain in apoptotic STAT function. We next linked the lack of apoptosis in the STAT1 and STAT2 
mutant cells to the constitutive and inducible expression of caspases and other apoptosis-regulating proteins. STAT1 was initially considered as a latent transcriptional factor translocates into the nucleus to regulate gene expression only when phosphorylated and activated by cytokines and other ligands. Our findings suggested that STAT1 might function as a nuclear transcriptional factor in the absence of phosphorylation. We found that the basal expression of caspases 2, 3, and 8 proteins is defective in U3A cells and its activation is induced only in 2 fTGH and U3A-R following bacterial RNA treatment. In contrast, the expression of these caspases was normal in the STAT2 mutant U6A. Thus, it seems likely that the requirement of STAT1 for bacterial RNA-mediated apoptosis acts in the absence of any phosphorylation of tyrosine 701. These results are in agreement with our previous results that demonstrated U3A cells reconstituted with the Y701F mutant of STAT1 are also sensitive to TNF $\alpha$-mediated apoptosis and normal for caspase 1, 2, and 3 gene expressions [24]. Analysis of gene expression in U3A cells and U3A-701 cells revealed that constitutive expression of many genes such as LMP2, MHC II, HSP70, and Bcl-xL are also regulated by unphosphorylated STAT1 [40]. Subsequent studies demonstrated that STAT1 is constitutively shuttling between the cytoplasm and nucleus prior to cytokine induction. Furthermore, it has been shown that tyrosine-phosphorylated and unphosphorylated STAT1 proteins are shuttled via independent pathways to distinct sets of target genes. Further support for the possibility that STATs might function as nuclear transcription factor without phosphorylation came from studies showed compelling evidence that unphosphorylated STAT1 (U-STAT1) and U-STAT2 molecules are detected in the nucleus of unstimulated cells and predominantly in dimeric structure prior to activation [50] [51] [52] [53] [54]. Our findings also suggest that promoters of the tested genes may contain recognition sites for STAT1 or STAT2. In agreement with this model, it has been demonstrated that the human caspase- 8 promoter region which regulates the constitutive and IFN-inducible gene expression has multiple GAS and ISRE transcription factor-binding sites.

Our results show that U3A-727 mutant cells were resistant to apoptosis and suggested that the serine-phosphorylation of STAT1 differentially regulates the basal and induced expression of the caspases proteins. In response to IFNs and a wide variety of stress and immunological signals, STAT1 is phosphorylated on serine 727 by MAP kinases. Serine phosphorylation of 727 is essential for maximal transcription activation and biological functions of STAT1 [30] [55]. It has been demonstrated that serine 727 phosphorylation of STAT1 is preferentially associated with some chromatin complexes and recruits histone acetyltransferases and other coactivators of transcription to the promoter of target genes. Mutations of STAT1 serine 727 differentially affect the expression of target genes at both basal and inducible levels [30] [56] [57]. In agreement with these findings, it has been indicated that serine 727 rather than tyrosine 701 of STAT1 is required for Fas-induced apoptosis and caspases-8 expression [58]. The biological significance of serine-phosphorylated STAT1 in mediating innate immunity 
and microbial infections has been also established in studies carried out in cultured cells or animal models [57] [59].

One of the best studied STAT1 activated genes is the transcriptional factor IRF1 which has been implicated in the regulation of apoptosis. We found that both U3Aand U6A cells were defective in IRF1 induction which suggested the involvement of IRF1 in regulating apoptotic response in these mutants. We observed that IRF1 expression reversed the apoptotic phenotype of U3A cells suggesting the importance of STAT1-regulated expression of IRF1 in apoptosis. It has been demonstrated that U-STAT1 monomers or dimers can bind to DNA by contacting one half of a palindromic GAS or GAS sequences respectively. However, the affinity of binding increases with P-STAT1 [40]. The IRF-1 protein is a good interacting partner for STAT1 to regulate the basal and inducible gene expression. For example, it has been demonstrated that STAT1 interacts with IRF1 as a dimer for binding the overlapping ICS2/GAS site on the LMP2 promoters to regulate its gene transcription [40]. Both STAT1 and IRF1 are essential for basal transcription of the LMP2 gene. Furthermore, the STAT1/IRF1 pathway is involved in regulation of caspases gene expression and induction of apoptosis because the promoter of these genes contains recognition sites for both STAT1 and IRF1 [60] [61] [62]. We also show that the basal and induced expression of p53 protein is defective in $\mathrm{U} 3 \mathrm{~A}$ and determined a physical association between the STAT1 and p53. This result suggested that STAT1 might function as a co-activator, a non-DNA binding transcriptional regulator, through a protein-protein interaction with a DNA-bound partner. Consistent with this possibility, it has been shown that STAT1 in MEF cells directly interacts with p53 in association that enhanced by DNA damaging stress. The induction of p53 responsive genes, such as Bax, Noxa, and Fas, was reduced in STAT-1-deficient cells [63]. The cooperation between the two proteins to induce apoptosis depends on p53 protein rather than p53 transcriptional activity [64].

The induction of apoptosis and the transcriptional regulation of caspase genes in certain cell lines have been linked to tyrosine phosphorylation and DNA binding activity of STATs [29] [30]. These observations suggested that the mechanisms that regulate the constitutive and inducible expression of STATs are distinct. Our results show that the U6A are resistant to apoptosis induced by bacterial RNA and we linked this response to the constitutive and inducible activation of some apoptosis regulating proteins. While the phosphorylation of STAT2 in U3A cells occurs normally, we found that the phosphorylation of STAT1 is decreased in U6A cells. We further show that the induction of IRF1 and formation of ISGF3 are also impaired in U6A cells. In U6A cells, it was reported that STAT2 is required for STAT1 activation and ISGF3 formation. All mutations that block STAT2 phosphorylation were also able to block STAT1 phosphorylation [65] [66]. The dependence of STAT1 phosphorylation on STAT2 suggested that in the formation of ISGF3, these two proteins may be phosphorylated sequentially and phosphorylated STAT2 may be required to allow unphosphorylated STAT1 to bind to the activated IFN- $\alpha$ receptor. In 
agreement with our results, it has been shown that the induction of IRF1 by IFN- $\alpha$ is also impaired in U6A cells and restored by STAT2. STAT2 is distinct among the STATs because it can constitutively bind to the IRF-9 which suggested that STAT2 localization may be regulated differently from STAT1. This hybrid can recapitulate the type I IFN biological response and producing a cellular antiviral response. Most important, the antiviral state generated by IRF9-STAT2 hybrid protein is independent of autocrine IFN signaling and inhibits both RNA and DNA viruses [66] [67]. It has been shown that the unphosphorylated STAT2 molecule constitutively shuttles in and out of the nucleus via association with IRF-9, but a functional nuclear export signal (NES) in the carboxyl terminus of STAT2 results in localization of the STAT2-IRF-9 complex to the cytoplasm (55). In agreements with our results, it was reported recently that STAT2-deficient human Jurkat and Daudi lymphoma cell lines are resistant to IFN $\alpha$ - and chemotherapy-induced apoptosis due to the deficiency in the caspases-dependent cell death and ISGF3-mediated gene activation. Tyrosine phosphorylation and nuclear localization of STAT2 are essential events for type I IFNs-induced apoptosis. Furthermore, the basal expression of a number of genes in STAT2 mutant cells that are known ISGs (PKR, STAT1, PML, and MCL1) is lower than that of the parental cell line [41] [68]. In addition to activation of STAT1 and STAT2, we show that stimulation with bacterial RNA also induces tyrosine phosphorylation of JAK1 in 2fTGH and HT1080 cells. Interestingly, this response was not only impaired in U3A and U6A cells, but also in serine 727 mutant of STAT1 which suggesting the positive impact of serine phosphorylation on tyrosine phosphorylation. Cell culture and knockout studies established the essential nonredundant role of JAK1 in mediating the biological responses to the major classes of cytokine receptors including both type I and II interferon receptors [35] [36]. Maximizing the transcription by serine phosphorylation was potentially explained by positive effects of serine phosphorylation on STAT1 tyrosine phosphorylation through increased affinity for activated receptors and/or JAKs [69]. However, interdependence of serine and tyrosine phosphorylation is not clear and involves a different subset of protein kinases. Serine 727 phosphorylation of STAT1 requires the phosphorylation of tyrosine 701 in response to IFN- $\gamma$, while under treatment with UV or lipopolysaccharide stimulation, it is independent of it. Furthermore, it has been shown that IFN $\gamma$-dependent induction of STAT1 serine-727 phosphorylation requires either JAK1 or JAK2 [57] [70].

\section{Conclusion}

We identified bacterial RNA as a novel inducer of apoptotic cell death. Our results indicated that the signaling pathways for the IFNs and bacterial RNA share common enzymes and transcription factors. However, STAT functions did not require tyrosine phosphorylation or dimerization for regulating apoptosis and maintenance of apoptosis-regulating protein expression, suggesting non-cytokine-dependent roles for STATs in these cells. In addition to 
bacterial immunity, the results presented here may also have implications in cellular pathophysiology and RNA-based therapy.

\section{Conflicts of Interest}

The authors declare no conflicts of interest regarding the publication of this paper.

\section{References}

[1] Bauer, S., Pigisch, S., Hangel, D., Kaufmann, A. and Hamm, S. (2008) Recognition of Nucleic Acid and Nucleic Acid Analogs by Toll-Like Receptors 7, 8 and 9. Immunobiology, 213, 315-328. https://doi.org/10.1016/j.imbio.2007.10.010

[2] Akira, S. and Hemmi, H. (2003) Recognition of Pathogen-Associated Molecular Patterns by TLR Family. Immunology Letters, 85, 85-95. https://doi.org/10.1016/S0165-2478(02)00228-6

[3] Alexopoulou, L. and Kontoyiannis, D. (2005) Intestinal Epithelial Barrier and Mucosal Immunity. Cellular and Molecular Life Sciences, 62, 1349-1358. https://doi.org/10.1007/s00018-005-5039-x

[4] Janssens, S. and Beyaert, R. (2003) Role of Toll-Like Receptors in Pathogen Recognition. Clinical Microbiology Reviews, 16, 637-646. https://doi.org/10.1128/CMR.16.4.637-646.2003

[5] Diebold, S.S., Montoya, M., Unger, H., Alexopoulou, L., Roy, P., Haswell, L.E., Al-Shamkhani, A., Flavell, R., Borrow, P. and Reis e Sousa, C. (2003) Viral Infection Switches Non-Plasmacytoid Dendritic Cells into High Interferon Producers. Nature, 424, 324-328. https://doi.org/10.1038/nature01783

[6] Alexopoulou, L., Holt, A.C., Medzhitov, R. and Flavell, R.A. (2001) Recognition of Double-Stranded RNA and Activation of NF-kappaB by Toll-Like Receptor 3. Nature, 413, 732-738. https://doi.org/10.1038/35099560

[7] Koski, G.K., Kariko, K., Xu, S., Weissman, D., Cohen, P.A. and Czerniecki, B.J. (2004) Cutting Edge: Innate Immune System Discriminates between RNA Containing Bacterial versus Eukaryotic Structural Features That Prime for High-Level IL-12 Secretion by Dendritic Cells. The Journal of Immunology, 172, 3989-3993. https://doi.org/10.4049/jimmunol.172.7.3989

[8] Kariko, K., Buckstein, M., Ni, H. and Weissman, D. (2005) Suppression of RNA Recognition by Toll-Like Receptors: The Impact of Nucleoside Modification and the Evolutionary Origin of RNA. Immunity, 23, 165-175.

https://doi.org/10.1016/j.immuni.2005.06.008

[9] Hamm, S., Heit, A., Koffler, M., Huster, K.M., Akira, S., Busch, D.H., Wagner, H. and Bauer, S. (2007) Immunostimulatory RNA Is a Potent Inducer of Antigen-Specific Cytotoxic and Humoral Immune Response in Vivo. International Immunology, 19, 297-304. https://doi.org/10.1093/intimm/dxl146

[10] Bourquin, C., Schmidt, L., Hornung, V., Wurzenberger, C., Anz, D., Sandholzer, N., Schreiber, S., Voelkl, A., Hartmann, G. and Endres, S. (2007) Immunostimulatory RNA Oligonucleotides Trigger an Antigen-Specific Cytotoxic T-Cell and IgG2a Response. Blood, 109, 2953-2960. https://doi.org/10.1182/blood-2006-07-033258

[11] Lau, C.M., Broughton, C., Tabor, A.S., Akira, S., Flavell, R.A., Mamula, M.J., Christensen, S.R., Shlomchik, M.J., Viglianti, G.A., Rifkin, I.R. and Marshak-Rothstein, A. (2005) RNA-Associated Autoantigens Activate B Cells by Combined B Cell Antigen Receptor/Toll-Like Receptor 7 Engagement. Journal of Experimental Medi- 
cine, 202, 1171-1177. https://doi.org/10.1084/jem.20050630

[12] Kanneganti, T.D., Ozoren, N., Body-Malapel, M., Amer, A., Park, J.H., Franchi, L., Whitfield, J., Barchet, W., Colonna, M., Vandenabeele, P., Bertin, J., Coyle, A., Grant, E.P., Akira, S. and Nunez, G. (2006) Bacterial RNA and Small Antiviral Compounds Activate Caspase-1 through Cryopyrin/Nalp3. Nature, 440, 233-236. https://doi.org/10.1038/nature04517

[13] Kanneganti, T.D., Body-Malapel, M., Amer, A., Park, J.H., Whitfield, J., Franchi, L., Taraporewala, Z.F., Miller, D., Patton, J.T., Inohara, N. and Nunez, G. (2006) Critical Role for Cryopyrin/Nalp3 in Activation of Caspase-1 in Response to Viral Infection and Double-Stranded RNA. The Journal of Biological Chemistry, 281, 36560-36568. https://doi.org/10.1074/jbc.M607594200

[14] Muruve, D.A., Petrilli, V., Zaiss, A.K., White, L.R., Clark, S.A., Ross, P.J., Parks, R.J. and Tschopp, J. (2008) The Inflammasome Recognizes Cytosolic Microbial and Host DNA and Triggers an Innate Immune Response. Nature, 452, 103. https://doi.org/10.1038/nature06664

[15] Kato, H., Takeuchi, O., Sato, S., Yoneyama, M., Yamamoto, M., Matsui, K., Uematsu, S., Jung, A., Kawai, T., Ishii, K.J., Yamaguchi, O., Otsu, K., Tsujimura, T., Koh, C.S., Reis e Sousa, C., Matsuura, Y., Fujita, T. and Akira, S. (2006) Differential Roles of MDA5 and RIG-I Helicases in the Recognition of RNA Viruses. Nature, 441, 101-105. https://doi.org/10.1038/nature04734

[16] Hornung, V., Ellegast, J., Kim, S., Brzozka, K., Jung, A., Kato, H., Poeck, H., Akira, S., Conzelmann, K.K., Schlee, M., Endres, S. and Hartmann, G. (2006) 5'-Triphosphate RNA Is the Ligand for RIG-I. Science (New York, NY), 314, 994-997. https://doi.org/10.1126/science.1132505

[17] Williams, B.R.G. (1995) The Role of the dsRNA-Activated Kinase, PKR, in Signal Transduction. Seminars in Virology, 6, 191-202. https://doi.org/10.1006/smvy.1995.0024

[18] Gitlin, L., Barchet, W., Gilfillan, S., Cella, M., Beutler, B., Flavell, R.A., Diamond, M.S. and Colonna, M. (2006) Essential Role of mda-5 in Type I IFN Responses to Polyriboinosinic: Polyribocytidylic Acid and Encephalomyocarditis Picornavirus. Proceedings of the National Academy of Sciences of the United States of America, 103, 8459-8464. https://doi.org/10.1073/pnas.0603082103

[19] Shuai, K., Ziemiecki, A., Wilks, A.F., Harpur, A.G., Sadowski, H.B., Gilman, M.Z. and Darnell, J.E. (1993) Polypeptide Signalling to the Nucleus through Tyrosine Phosphorylation of Jak and Stat Proteins. Nature, 366, 580-583.

https://doi.org/10.1038/366580a0

[20] Silvennoinen, O., Ihle, J.N., Schlessinger, J. and Levy, D.E. (1993) Interferon-Induced Nuclear Signalling by Jak Protein Tyrosine Kinases. Nature, 366, 583-585. https://doi.org/10.1038/366583a0

[21] Muller, M., Laxton, C., Briscoe, J., Schindler, C., Improta, T., Darnell, J.E., Stark, G.R. and Kerr, I.M. (1993) Complementation of a Mutant Cell Line: Central Role of the $91 \mathrm{kDa}$ Polypeptide of ISGF3 in the Interferon-Alpha and -Gamma Signal Transduction Pathways. EMBOJ, 12, 4221-4228. https://doi.org/10.1002/j.1460-2075.1993.tb06106.x

[22] Fu, X.Y., Schindler, C., Improta, T., Aebersold, R. and Darnell, J.E. (1992) The Proteins of ISGF-3, the Interferon Alpha-Induced Transcriptional Activator, Define a Gene Family Involved in Signal Transduction. Proceedings of the National Academy of Sciences of the United States of America, 89, 7840-7843.

https://doi.org/10.1073/pnas.89.16.7840 
[23] Nallagatla, S.R., Hwang, J., Toroney, R., Zheng, X., Cameron, C.E. and Bevilacqua, P.C. (2007) 5'-Triphosphate-dependent Activation of PKR by RNAs with Short Stem-Loops. Science, 318, 1455-1458. https://doi.org/10.1126/science.1147347

[24] Kumar, A., Commane, M., Flickinger, T.W., Horvath, C.M. and Stark, G.R. (1997) Defective TNF-Alpha-Induced Apoptosis in STAT1-Null Cells Due to Low Constitutive Levels of Caspases. Science, 278, 1630-1632. https://doi.org/10.1126/science.278.5343.1630

[25] McKendry, R., John, J., Flavell, D., Muller, M., Kerr, I.M. and Stark, G.R. (1991) High-Frequency Mutagenesis of Human Cells and Characterization of a Mutant Unresponsive to Both Alpha and Gamma Interferons. Proceedings of the National Academy of Sciences of the United States of America, 88, 11455-11459. https://doi.org/10.1073/pnas.88.24.11455

[26] Pellegrini, S., John, J., Shearer, M., Kerr, I.M. and Stark, G.R. (1989) Use of a Selectable Marker Regulated by Alpha Interferon to Obtain Mutations in the Signaling Pathway. Molecular and Cellular Biology, 9, 4605-4612. https://doi.org/10.1128/MCB.9.11.4605

[27] Kumar, A., Kumar, A., Michael, P., Brabant, D., Parissenti, A.M., Ramana, C.V., Xu, X. and Parrillo, J.E. (2005) Human Serum from Patients with Septic Shock Activates Transcription Factors STAT1, IRF1, and NF- $\kappa$ B and Induces Apoptosis in Human Cardiac Myocytes. The Journal of Biological Chemistry, 280, 42619-42626. https://doi.org/10.1074/jbc.M508416200

[28] Herrmann, M., Lorenz, H.M., Voll, R., Grunke, M., Woith, W. and Kalden, J.R. (1994) A Rapid and Simple Method for the Isolation of Apoptotic DNA Fragments. Nucleic Acids Research, 22, 5506-5507. https://doi.org/10.1093/nar/22.24.5506

[29] Shuai, K., Stark, G.R., Kerr, I.M. and Darnell, J.E. (1993) A Single Phosphotyrosine Residue of Stat91 Required for Gene Activation by Interferon-Gamma. Science, 261, 1744-1746. https://doi.org/10.1126/science.7690989

[30] Wen, Z., Zhong, Z. and Darnell, J.E. (1995) Maximal Activation of Transcription by Stat1 and Stat3 Requires Both Tyrosine and Serine Phosphorylation. Cell, 82, 241-250. https://doi.org/10.1016/0092-8674(95)90311-9

[31] Heim, M.H., Kerr, I.M., Stark, G.R. and Darnell, J.E. (1995) Contribution of STAT SH2 Groups to Specific Interferon Signaling by the Jak-STAT Pathway. Science, 267, 1347-1349. https://doi.org/10.1126/science.7871432

[32] Schindler, C., Fu, X.Y., Improta, T., Aebersold, R. and Darnell, J.E. (1992) Proteins of Transcription Factor ISGF-3: One Gene Encodes the 91- and 84-kDa ISGF-3 Proteins That Are Activated by Interferon alpha. Proceedings of the National Academy of Sciences of the United States of America, 89, 7836-7839. https://doi.org/10.1073/pnas.89.16.7836

[33] Fulda, S. and Debatin, K.M. (2002) IFNgamma Sensitizes for Apoptosis by Upregulating caspase-8 Expression through the Stat1 Pathway. Oncogene, 21, 2295-2308. https://doi.org/10.1038/sj.onc.1205255

[34] Chin, Y.E., Kitagawa, M., Kuida, K., Flavell, R.A. and Fu, X.Y. (1997) Activation of the STAT Signaling Pathway Can Cause Expression of Caspase-1 and Apoptosis. Molecular and Cellular Biology, 17, 5328-5337. https://doi.org/10.1128/MCB.17.9.5328

[35] Muller, M., Briscoe, J., Laxton, C., Guschin, D., Ziemiecki, A., Silvennoinen, O., Harpur, A.G., Barbieri, G., Witthuhn, B.A. and Schindler, C. (1993) The Protein Tyrosine Kinase JAK1 Complements Defects in Interferon- $\alpha / \beta$ and $-\gamma$ Signal Transduction. Nature, 366, 129-135. https://doi.org/10.1038/366129a0 
[36] Rodig, S.J., Meraz, M.A., White, J.M., Lampe, P.A., Riley, J.K., Arthur, C.D., King, K.L., Sheehan, K.C., Yin, L., Pennica, D., Johnson, E.M. and Schreiber, R.D. (1998) Disruption of the Jak1 Gene Demonstrates Obligatory and Nonredundant Roles of the Jaks in Cytokine-Induced Biologic Responses. Cell, 93, 373-383. https://doi.org/10.1016/S0092-8674(00)81166-6

[37] Matin, S.F., Rackley, R.R., Sadhukhan, P.C., Kim, M.S., Novick, A.C. and Bandyopadhyay, S.K. (2001) Impaired Alpha-Interferon Signaling in Transitional Cell Carcinoma: Lack of p48 Expression in 5637 Cells. Cancer Research, 61, 2261-2266.

[38] Wong, L.H., Krauer, K.G., Hatzinisiriou, I., Estcourt, M.J., Hersey, P., Tam, N.D., Edmondson, S., Devenish, R.J. and Ralph, S.J. (1997) Interferon-Resistant Human Melanoma Cells Are Deficient in ISGF3 Components, STAT1, STAT2, and p48-ISGF3gamma. The Journal of Biological Chemistry, 272, 28779-28785. https://doi.org/10.1074/jbc.272.45.28779

[39] Leung, S., Qureshi, S.A., Kerr, I.M., Darnell, J.E. and Stark, G.R. (1995) Role of STAT2 in the Alpha Interferon Signaling Pathway. Molecular and Cellular Biology, 15, 1312-1317. https://doi.org/10.1128/MCB.15.3.1312

[40] Chatterjee-Kishore, M., Wright, K.L., Ting, J.P. and Stark, G.R. (2000) How Stat1 Mediates Constitutive Gene Expression: A Complex of Unphosphorylated Stat1 and IRF1 Supports Transcription of the LMP2 Gene. EMBOJ, 19, 4111-4122. https://doi.org/10.1093/emboj/19.15.4111

[41] Du, Z., Fan, M., Kim, J.G., Eckerle, D., Lothstein, L., Wei, L. and Pfeffer, L.M. (2009) Interferon-Resistant Daudi Cell Line with a Stat2 Defect Is Resistant to Apoptosis Induced by Chemotherapeutic Agents. The Journal of Biological Chemistry, 284, 27808-27815. https://doi.org/10.1074/jbc.M109.028324

[42] Paladugu, B., Kumar, A., Parrillo, J.E., Der, S., Osman, J., Mensing, J., Falvo, L., Xu, X. and Kumar, A. (2004) Bacterial DNA and RNA Induce Rat Cardiac Myocyte Contraction Depression in Vitro. Shock, 21, 364-369. https://doi.org/10.1097/00024382-200404000-00012

[43] Brabant, D., Michael, P., Bleiblo, F., Saleh, M., Narain, R., Tai, T.C., Ramana, C.V., Parrillo, J.E., Kumar, A. and Kumar, A. (2011) Septic Sera Induces Apoptosis and DNA Fragmentation Factor 40 Activation in Fibroblasts. Biochemical and Biophysical Research Communications, 412, 260-265. https://doi.org/10.1016/j.bbrc.2011.07.080

[44] Hussein, S., Michael, P., Brabant, D., Omri, A., Narain, R., Passi, K., Ramana, C.V., Parrillo, J.E., Kumar, A., Parissenti, A. and Kumar, A. (2009) Characterization of Human Septic Sera Induced Gene Expression Modulation in Human Myocytes. International Journal of Clinical and Experimental Medicine, 2, 131-148.

[45] Stacey, K.J., Sweet, M.J. and Hume, D.A. (1996) Macrophages Ingest and Are Activated by Bacterial DNA. The Journal of Immunology, 157, 2116-2122.

[46] Sparwasser, T., Miethke, T., Lipford, G., Borschert, K., Hacker, H., Heeg, K. and Wagner, H. (1997) Bacterial DNA Causes Septic Shock. Nature, 386, 336-337. https://doi.org/10.1038/386336a0

[47] Chiu, Y.H., Macmillan, J.B. and Chen, Z.J. (2009) RNA Polymerase III Detects Cytosolic DNA and Induces Type I Interferons through the RIG-I Pathway. Cell, 138, 576-591. https://doi.org/10.1016/j.cell.2009.06.015

[48] Eberle, F., Sirin, M., Binder, M. and Dalpke, A.H. (2009) Bacterial RNA Is Recognized by Different Sets of Immunoreceptors. European Journal of Immunology, 39, 2537-2547. https://doi.org/10.1002/eji.200838978

[49] Zakharova, N., Lymar, E.S., Yang, E., Malik, S., Zhang, J.J., Roeder, R.G. and Dar- 
nell, J.E. (2003) Distinct Transcriptional Activation Functions of STAT1 $\alpha$ and STAT $1 \beta$ on DNA and Chromatin Templates. The Journal of Biological Chemistry, 278, 43067-43073. https://doi.org/10.1074/jbc.M308166200

[50] Meyer, T., Begitt, A., Lodige, I., van Rossum, M. and Vinkemeier, U. (2002) Constitutive and IFN-gamma-Induced Nuclear Import of STAT1 Proceed through Independent Pathways. EMBOJ, 21, 344-354. https://doi.org/10.1093/emboj/21.3.344

[51] Braunstein, J., Brutsaert, S., Olson, R. and Schindler, C. (2003) STATs Dimerize in the Absence of Phosphorylation. The Journal of Biological Chemistry, 278, 34133-34140. https://doi.org/10.1074/jbc.M304531200

[52] Yang, J. and Stark, G.R. (2008) Roles of Unphosphorylated STATs in Signaling. Cell Research, 18, 443-451. https://doi.org/10.1038/cr.2008.41

[53] Banninger, G. and Reich, N.C. (2004) STAT2 Nuclear Trafficking. The Journal of Biological Chemistry, 279, 39199-39206. https://doi.org/10.1074/jbc.M400815200

[54] Mao, X., Ren, Z., Parker, G.N., Sondermann, H., Pastorello, M.A., Wang, W., McMurray, J.S., Demeler, B., Darnell, J.E. and Chen, X. (2005) Structural Bases of Unphosphorylated STAT1 Association and Receptor Binding. Molecular Cell, 17, 761-771. https://doi.org/10.1016/j.molcel.2005.02.021

[55] Kovarik, P., Stoiber, D., Eyers, P.A., Menghini, R., Neininger, A., Gaestel, M., Cohen, P. and Decker, T. (1999) Stress-Induced Phosphorylation of STAT1 at Ser727 Requires p38 Mitogen-Activated Protein Kinase Whereas IFN- $\gamma$ Uses a Different Signaling Pathway. Proceedings of the National Academy of Sciences of the United States of America, 96, 13956-13961. https://doi.org/10.1073/pnas.96.24.13956

[56] Sadzak, I., Schiff, M., Gattermeier, I., Glinitzer, R., Sauer, I., Saalmuller, A., Yang, E., Schaljo, B. and Kovarik, P. (2008) Recruitment of Stat1 to Chromatin Is Required for Interferon-Induced Serine Phosphorylation of Stat1 Transactivation Domain. Proceedings of the National Academy of Sciences of the United States of America, 105, 8944-8949. https://doi.org/10.1073/pnas.0801794105

[57] Kovarik, P., Mangold, M., Ramsauer, K., Heidari, H., Steinborn, R., Zotter, A., Levy, D.E., Muller, M. and Decker, T. (2001) Specificity of Signaling by STAT1 Depends on SH2 and C-Terminal Domains That Regulate Ser727 Phosphorylation, Differentially Affecting Specific Target Gene Expression. EMBOJ, 20, 91-100. https://doi.org/10.1093/emboj/20.1.91

[58] Stephanou, A., Scarabelli, T.M., Brar, B.K., Nakanishi, Y., Matsumura, M., Knight, R.A. and Latchman, D.S. (2001) Induction of Apoptosis and Fas Receptor/Fas Ligand Expression by Ischemia/Reperfusion in Cardiac Myocytes Requires Serine 727 of the STAT-1 Transcription Factor but Not Tyrosine 701. The Journal of Biological Chemistry, 276, 28340-28347. https://doi.org/10.1074/jbc.M101177200

[59] Varinou, L., Ramsauer, K., Karaghiosoff, M., Kolbe, T., Pfeffer, K., Muller, M. and Decker, T. (2003) Phosphorylation of the Stat1 Transactivation Domain Is Required for Full-Fledged IFN-gamma-Dependent Innate Immunity. Immunity, 19, 793-802. https://doi.org/10.1016/S1074-7613(03)00322-4

[60] Casciano, I., De Ambrosis, A., Croce, M., Pagnan, G., Di Vinci, A., Allemanni, G., Banelli, B., Ponzoni, M., Romani, M. and Ferrini, S. (2004) Expression of the Caspase-8 Gene in Neuroblastoma Cells Is Regulated through an Essential Interferon-Sensitive Response Element (ISRE). Cell Death and Differentiation, 11, 131-134. https://doi.org/10.1038/sj.cdd.4401327

[61] De Ambrosis, A., Casciano, I., Croce, M., Pagnan, G., Radic, L., Banelli, B., Di Vinci, 
A., Allemanni, G., Tonini, G.P., Ponzoni, M., Romani, M. and Ferrini, S. (2007) An Interferon-Sensitive Response Element Is Involved in Constitutive caspase-8 Gene Expression in Neuroblastoma Cells. International Journal of Cancer, 120, 39-47. https://doi.org/10.1002/ijc.22173

[62] Ruiz-Ruiz, C., Ruiz de Almodovar, C., Rodriguez, A., Ortiz-Ferron, G., Redondo, J.M. and Lopez-Rivas, A. (2004) The Up-Regulation of Human Caspase-8 by Interferon- $\gamma$ in Breast Tumor Cells Requires the Induction and Action of the Transcription Factor Interferon Regulatory Factor-1. The Journal of Biological Chemistry, 279, 19712-19720. https://doi.org/10.1074/jbc.M313023200

[63] Townsend, P.A., Scarabelli, T.M., Davidson, S.M., Knight, R.A., Latchman, D.S. and Stephanou, A. (2004) STAT-1 Interacts with p53 to Enhance DNA Damage-Induced Apoptosis. The Journal of Biological Chemistry, 279, 5811-5820.

https://doi.org/10.1074/jbc.M302637200

[64] Youlyouz-Marfak, I., Gachard, N., Le Clorennec, C., Najjar, I., Baran-Marszak, F., Reminieras, L., May, E., Bornkamm, G.W., Fagard, R. and Feuillard, J. (2008) Identification of a Novel p53-Dependent Activation Pathway of STAT1 by Antitumourgenotoxic Agents. Cell Death and Differentiation, 15, 376-385. https://doi.org/10.1038/sj.cdd.4402270

[65] Qureshi, S.A., Leung, S., Kerr, I.M., Stark, G.R. and Darnell, J.E. (1996) Function of Stat2 Protein in Transcriptional Activation by Alpha Interferon. Molecular and Cellular Biology, 16, 288-293. https://doi.org/10.1128/MCB.16.1.288

[66] Bluyssen, H.A. and Levy, D.E. (1997) Stat2 Is a Transcriptional Activator That Requires Sequence-Specific Contacts Provided by Stat 1 and 48 for Stable Interaction with DNA. The Journal of Biological Chemistry, 272, 4600-4605. https://doi.org/10.1074/jbc.272.7.4600

[67] Kraus, T.A., Lau, J.F., Parisien, J.P. and Horvath, C.M. (2003) A Hybrid IRF9-STAT2 Protein Recapitulates Interferon-Stimulated Gene Expression and Antiviral Response. The Journal of Biological Chemistry, 278, 13033-13038. https://doi.org/10.1074/jbc.M212972200

[68] Romero-Weaver, A.L., Wang, H.W., Steen, H.C., Scarzello, A.J., Hall, V.L., Sheikh, F., Donnelly, R.P. and Gamero, A.M. (2010) Resistance to IFN-alpha-Induced Apoptosis Is Linked to a Loss of STAT2. Molecular Cancer Research, 8, 80-92. https://doi.org/10.1158/1541-7786.MCR-08-0344

[69] Decker, T. and Kovarik, P. (2000) Serine Phosphorylation of STATs. Oncogene, 19, 2628-2637. https://doi.org/10.1038/sj.onc.1203481

[70] Nguyen, H., Ramana, C.V., Bayes, J. and Stark, G.R. (2001) Phosphatidylinositol 3-Kinase in Interferon- $\gamma$-Dependent Phosphorylation of STAT1 on Serine 727 and Activation of Gene Expression. The Journal of Biological Chemistry, 276, 33361-33368. https://doi.org/10.1074/jbc.M105070200 